\title{
An Epidemiological Investigation into the Relative Importance of Age and Oral Hygiene Status as Determinants of Periodontitis
}

\author{
H. M. ABDELLATIF and B. A. BURT
}

Program in Dental Public Health, School of Public Health, The University of Michigan, Ann Arbor, Michigan 48109

\begin{abstract}
The objective of this study was to assess the relative effects of age and oral hygiene on the progression of periodontitis by estimating incidence from age-specific prevalence. This study analyzed data from a representative national sample of 14,690 dentate Americans, aged from 15 to 74, seen in the first National Health and Nutrition Examination Survey (NHANES I) in 1971-1974. Results showed that the rate of increase in the estimated incidence of periodontitis with age, throughout all age groups, is much higher among subjects with poor oral hygiene than among those with good oral hygiene. Oral hygiene was confirmed as the most important predictor for periodontitis; in all age groups, more than 95\% of those examined with good oral hygiene did not have periodontitis. It was concluded that the effect of age on the progression of periodontitis could therefore be considered negligible when good oral hygiene is maintained.
\end{abstract}

J Dent Res 66(1):13-18, January, 1987

\section{Introduction.}

Numerous epidemiological studies, summarized in a series of reviews, show that diseases of the periodontium are among the most common human afflictions (Chilton, 1950; Scherp, 1964; Waerhaug, 1966; Ramfjord et al., 1968; Chilton and Millett, 1977; WHO, 1978; Sheiham, 1979). Results of these reports, despite their variety of research approaches among populations with divergent cultural, socio-economic, and geographic backgrounds, have been remarkably uniform with respect to the strong positive association between periodontal diseases and both age and oral plaque deposits. Greater tooth loss in older age groups has also usually been attributed to the effects of periodontitis, long accepted as the major source of tooth loss in adults (Becker et al., 1979; McHugh et al., 1982).

The cross-sectional nature of those earlier studies, however, may have produced misleading conclusions, because they were often interpreted to suggest that periodontal destruction progressed with increasing age in a nearly linear fashion. The use of composite indices, which recorded scores for both gingivitis and periodontitis on one scale, also tended to confuse the true picture of the natural history of periodontitis. Unfortunately, many of these earlier studies did not account for oral hygiene status when assessing the effect of age on periodontal diseases, but the association between age and periodontal diseases is less clear when good oral hygiene is maintained. Boyle et al. (1973) stated that age has only a slight effect on reduction of alveolar crest height when dental and periodontal health are maintained. The longitudinal study of Suomi et al. (1971) demonstrated that gingivitis and periodontitis were consistently associated with poorer levels of oral hygiene, regardless of age, while the longitudinal studies of Löe et al. (1978a, 1978b) and Anerud et al. (1979) have indicated that periodontal disease development was virtually halted in adults who maintained a high degree of oral hygiene.

More recently, a series of epidemiological studies has shown that the prevalence of advanced periodontitis, meaning at least

Received for publication May 5, 1986

Accepted for publication September 8, 1986 one pocket of $6 \mathrm{~mm}$ or more, is not as common in older persons as was previously thought (Hugoson and Jordan, 1982; Beck et al., 1984; Burt et al., 1985). These cross-sectional surveys are in accord with recent clinical studies which challenge the long-held belief that periodontitis progression is more-or-less linear (Lindhe et al., 1983) and evenly distributed in the mouth (Socransky et al., 1984). Lindhe et al. (1983) showed that a site which has developed disease during one time period does not necessarily deteriorate further over time. The data from this study do not support the hypothesis that periodontal disease in a given individual is a slowly progressive disease with age, but rather imply that certain sites in some individuals are affected by progressive disease when oral hygiene is poor. These results are in agreement with those of Socransky et al. (1984), Haffajee et al. (1982), and Goodson et al. (1982)-a series of studies which proposed the "random burst" model of periodontal disease progression. While this model of periodontal disease awaits total acceptance (Imery, 1986), it does not view periodontitis as age-dependent.

It can be argued that in cross-sectional studies associating periodontal disease with age, both risk factors and disease are ascertained at the same time, thus failing to establish the temporal sequence of events necessary for drawing causal inferences (Kleinbaum et al., 1982). In other words, such studies do not differentiate between age effect and cohort effect, the latter defined by Last (1983) as the variation in health status that arises from the different causal factors to which each birth cohort is exposed. Longitudinal studies could distinguish between age effect and cohort effect, but in representative populations they are expensive and difficult to conduct. Instead, statistical methods which can use cross-sectional data to distinguish between age and cohort effects would assist in further defining the natural history of periodontitis.

This paper further addresses the nature of age as a risk factor in periodontitis, and does so using cross-sectional data. Generally it is impossible to estimate incidence from age-specific prevalence, because prevalence is a function of both incidence and duration of disease, and there is no simple relationship among these three factors. However, for non-fatal diseases that are usually considered irreversible, such as periodontitis, a statistical model suggested by Leske et al. (1981) can be applied to estimate incidence from age-specific prevalence. This paper analyzes data from the first National Health and Nutritional Examination Survey (NHANES I), conducted from 1971 to 1974 , to determine whether the incidence of periodontitis increases with age in a representative sample of the U.S. population.

\section{Materials and methods.}

Detailed descriptions of NHANES I can be found elsewhere (Kelley and Harvey, 1979; Burt et al., 1982; Ismail et al., 1983). Briefly, NHANES I was a comprehensive cross-sectional survey of a national sample of Americans aged from 1 to 74 , intended to provide an assessment of the health and nutritional status of the American people. It employed multistage sampling procedures to draw a representative sample of 
28,043 persons; the response rate for clinical medical/dental examinations was $74 \%$. The sampling procedure employed a cluster design, as well as deliberate oversampling of low-income persons, pre-school children, women of childbearing age, and elderly persons thought to be at higher risk of malnutrition.

All respondents answered a detailed questionnaire on health history, and medical and dental examinations were provided. In the dental segment of the survey, periodontal disease and oral hygiene status, in addition to other assessments of oral health, were measured by 10 trained dentists at 65 examination locations. The Periodontal Index (PI) of Russell (1956, 1967) was used to assess the presence and severity of periodontal disease, and oral hygiene status was recorded by the Simplified Oral Hygiene Index (OHI-S) of Greene and Vermillion (1964). For the analysis in this paper, the presence of periodontitis was determined according to the treatment need criteria used in NHANES I (Kelly and Harvey, 1979); gingivitis is not included in this analysis. Oral hygiene was also based on treatment need criteria, and was classified as good or poor according to the examining dentists' judgment of need for professional removal of calculus and plaque deposits.

This analysis is restricted to dentate persons aged from 15 to 74 (a total of 14,690 persons) in the NHANES I survey. Other variables from the NHANES I examination and interview used in this study include gender, race, education, family income, dental visit frequency, toothbrushing frequency, and number of teeth present.

Statistical analysis. - The basis of this analysis is to estimate incidence from age-specific prevalence data. In using the technique of Leske et al. (1981) for estimating incidence, one must make the following assumptions: (1) The duration of periodontitis is life-long after diagnosis; (2) the mortality risk is the same in diseased and non-diseased individuals; and (3) periodontitis is a stable disease in a stable population, i.e., disease incidence and population composition remain constant over time. Under assumptions 1 and 3 , the number of persons with periodontitis at the end of an age interval will equal those with the condition at the beginning of the interval and alive at the end of it, plus those developing periodontitis during it. This can be expressed as

$$
N_{x+1} P_{x+1}=N_{x} P_{x}\left(1-q_{x}\right)+\pi_{x}\left(N_{x}-N_{x} P_{x}\right)\left(1-q_{x}\right)
$$

where

$$
\begin{array}{ll}
\mathrm{N}_{\mathrm{x}} & =\begin{array}{l}
\text { population at the beginning of age interval } \mathrm{x} ; \\
\mathrm{P}_{\mathrm{x}}
\end{array}=\begin{array}{l}
\text { prevalence proportion at beginning of age in- } \\
\text { terval } \mathrm{x}, 0 \leq \mathrm{P}_{\mathrm{x}} \leq 1 ;
\end{array} \\
\mathrm{q}_{\mathrm{x}} & =\begin{array}{l}
\text { probability of dying during age interval } \mathrm{x}, 0 \leq \\
\mathrm{P}_{\mathrm{x}} \leq 1 ;
\end{array} \\
\pi_{\mathrm{x}} & =\begin{array}{l}
\text { probability of developing the disease during age } \\
\text { interval } \mathrm{x}, 0 \leq \pi_{\mathrm{x}} \leq 1 ;
\end{array} \\
\mathrm{x}+1= & \text { age interval immediately following age interval }
\end{array}
$$
$\mathrm{X}$.

Then

$$
\pi_{x}=\frac{N_{x+1} P_{x+1}-N_{x} P_{x}\left(1-q_{x}\right)}{\left(N_{x}-N_{x} P_{x}\right)\left(1-q_{x}\right)}
$$

According to assumption $2, \mathrm{~N}_{\mathrm{x}+1}=\mathrm{N}_{\mathrm{x}}\left(1-\mathrm{q}_{\mathrm{x}}\right)$, thus

$$
\pi_{x}=\frac{P_{x+1}-P_{x}}{1-P_{x}}
$$

By definition, incidence $\left(I_{x}\right)$ is the number of cases of disease developing in interval $x$ divided by the average population at risk (Last, 1983), i.e.,

$$
\begin{gathered}
I_{x}=\frac{\pi_{x}\left(N_{x}-N_{x} P_{x}\right)\left(1-q_{x}\right)+\pi_{x}\left(N_{x}-N_{x} P_{x}\right) q_{x} f_{x}}{N_{x}-N_{x} P_{x}-\left[\left(N_{x}-N_{x} P_{x}\right) \frac{1}{2} q_{x}\right]} \\
\text { or } \\
I_{x}=\frac{\pi_{x}\left[1-q_{x}\left(1-f_{x}\right)\right]}{\left(1-\frac{1}{2} q_{x}\right)}
\end{gathered}
$$

where $f_{x}$ is the fraction of $\pi_{x}\left(N_{x}-N_{x} P_{x}\right) q_{x}$ where disease occurs before death. $\pi_{x}$ is a probability, not a rate, and is different from the incidence rate $I_{x}, \pi_{x}$ is a net risk, i.e., the probability of disease in the absence of competing risk of death, while $I_{x}$ is the incidence rate in the presence of competing mortality. By making the assumption that the times until death and until developing the disease are equal, so that $f_{x}=1 / 2$, then $I_{x}$ reduces to $\pi_{x}$. The incidence rate can be estimated from Equation 1. However, as mentioned earlier, there are conceptual differences between $I_{x}$ and $\pi_{x}$.

The next approach was the use of logistic regression as a more analytical investigation into the relationship between age and periodontitis by correlating the occurrence or non-occurrence of periodontitis to age for all individuals in the sample. The logistic regression model is also used to account for other pertinent factors such as oral hygiene, income, number of teeth in the mouth, frequency of toothbrushing, dental visit frequency, gender, race, education, and family income. The predictive power criterion (Berki et al., 1985) was used to decide upon the best model. From this data set, estimates of the regression coefficients were computed, and the probabilities of periodontitis were estimated from these age-specific and oral hygiene-specific coefficients; these probabilities are actually estimates of age-specific prevalences. They differ from the original prevalence in that they are fitted values from the logistic regression-better to the extent that the logistic model is appropriate for the general population, since the fitted values from all regressions are less variable. From these estimates of prevalence, incidences were estimated using the formula of Leske et al. (1981) presented previously.

In the statistical analysis, two measures of association between periodontitis and the best predictive variables were computed. By using the estimated incidence, we calculated the relative risk for each age group, and by use of the coefficient of the best predictors for the disease and the risk factor, the measure of association is expected to equal unity. Values of the measure of association larger than unity indicate the presence of an association between the disease and the risk factor. The etiologic fraction among exposed persons-defined by Last (1983) as the proportion of persons with disease among those exposed that can be attributed to exposure to the risk factorwas also calculated for each age group.

Significant tests are not included in the results, because for groups of this size even trivial differences are usually statistically significant.

\section{Results.}

Information about distribution of periodontitis by age (Table 1) follows the expected patterns. The prevalence of periodontitis increases with age up through age group 55-59 (where the prevalence is $20.8 \%$ ), then it shows a slight reduction which could be explained by the greater loss of affected teeth in the older age groups. Table 2 shows the extent of periodontitis among subjects stratified by two levels of oral hygiene. Al- 
TABLE 1

PERCENT DISTRIBUTION OF THE SAMPLE SUBJECTS AGED 1574 BY PERIODONTITIS STATUS* AND AGE, UNITED STATES, $1971-74$

\begin{tabular}{cccc}
\hline \hline & & \multicolumn{2}{c}{ Status } \\
\cline { 3 - 4 } Age Group & $\mathrm{n}$ & \% without periodontitis & \% with periodontitis \\
\hline $15-19$ & 1559 & 95.8 & 4.2 \\
$20-24$ & 1756 & 92.3 & 7.7 \\
$25-29$ & 1508 & 91.0 & 9.0 \\
$30-34$ & 1192 & 85.3 & 14.7 \\
$35-39$ & 1160 & 81.7 & 18.3 \\
$40-44$ & 1168 & 81.5 & 18.5 \\
$45-49$ & 787 & 79.9 & 20.1 \\
$50-54$ & 814 & 80.9 & 19.1 \\
$55-59$ & 685 & 79.2 & 20.8 \\
$60-64$ & 5823 & 83.4 & 16.6 \\
$65-69$ & 2013 & 83.3 & 16.7 \\
$\geq 70$ & 1466 & 86.6 & 13.4 \\
\hline Total & 14690 & 86.2 & 13.8 \\
\hline
\end{tabular}

*Determined by examiner judgment of treatment need for periodontitis.

though the prevalence of periodontitis increases with age in both strata, the prevalence within each age group among those with poor oral hygiene is at least eight times greater than among those with good oral hygiene.

Table 3 presents the estimated incidences based on the prevalence obtained in the sample, by use of the formula of Leske et al. (1981). A decrease of age-specific prevalence from one group to the next results in a negative incidence. Because such a value is meaningless in this analysis, a value of zero has been substituted. Not unexpectedly, Table 3 shows that although there is variability of the estimated incidence throughout the age groups, due to the cross-sectional nature of the study, the estimated incidence rates appear to be higher among subjects with poor oral hygiene than among those with good oral hygiene.

The logistic regression model is used to account for differences between those with and without periodontitis as affected by age, oral hygiene, gender, race, income, education, number of teeth in the mouth, dental visit frequency, and frequency of toothbrushing. The predictive power criterion is used for evaluating the regression models. Oral hygiene is found to be the most important independent variable from among those listed, with a predictive power of $0.769\left(\chi^{2}=2691.01\right)$, followed by age, with a predictive power of $0.675\left(\chi^{2}=251.46\right)$. The predictive power for the model containing both variables of age and oral hygiene is 0.738 , in comparison with the model containing all covariates, where the predictive power is 0.740 . From this comparison, it is clear that the model containing all covariates did not contribute much beyond the model containing only age and oral hygiene variables. Table 4 presents the estimated coefficients for the logistic regression analysis for the two main predictors of periodontitis, oral hygiene and age.

Based on these regression coefficients, a fitted prevalence was computed for each age group stratified by oral hygiene levels. Table 5 shows that prevalence increases throughout all age groups in both oral hygiene strata. Again, the fitted prevalence for subjects with poor oral hygiene is much higher than for those with good oral hygiene.

Table 6 presents the estimated incidences based on fitted prevalences using the formula of Leske et al. (1981). In both oral hygiene strata, the estimated incidence of periodontitis increases slightly with age, but the increase of estimated incidence in the good-oral-hygiene group is less than in those with poor oral hygiene. The relative risk for each age group ranges from 17.2 to 8.2 , indicating a strong association between disease and oral hygiene. In Table 6 , the values of the calculated etiologic fraction among exposed persons range from $94 \%$ to $88 \%$, indicating that at least $88 \%$ of periodontitis among all exposed age groups can be attributed to poor oral hygiene.

\section{Discussion.}

Age is considered a determinant of many diseases, i.e., the incidence rates of disease vary with advancing age. Although longitudinal study is required to assess most validly the effect of age on disease, the question of practicality is raised when one studies a disease such as periodontitis: Studies of some 40 years would be required - clearly not a practical proposition. Prevalence data are so much easier to obtain than incidence data in population studies.

The method of estimating age-specific incidence from prevalence data (Leske et al., 1981), employed in this paper, would be a valuable research tool if the assumptions on which it is based are valid. The first assumption is that periodontitis is irreversible, a question on which there is some uncertainty. Irreversibility has been challenged by data which suggest that spontaneous healing of periodontal lesions can occur in the absence of therapy (Goodson et al., 1982; Lindhe et al., 1983;

TABLE 2

PREVALENCE OF PERIODONTITIS* IN THE ANALYZED SAMPLE BY AGE STRATIFIED BY ORAL HYGIENE TREATMENT NEEDS**, UNITED STATES, 1971-74

\begin{tabular}{|c|c|c|c|c|c|c|}
\hline \multirow[b]{3}{*}{ Age Group } & \multicolumn{6}{|c|}{ Oral Hygiene } \\
\hline & \multicolumn{3}{|c|}{ Good } & \multicolumn{3}{|c|}{ Poor } \\
\hline & $\mathrm{n}$ & $\begin{array}{c}\% \text { without } \\
\text { periodontitis }\end{array}$ & $\begin{array}{c}\% \text { with } \\
\text { periodontitis }\end{array}$ & $\mathbf{n}$ & $\begin{array}{l}\% \text { without } \\
\text { periodontitis }\end{array}$ & $\begin{array}{c}\% \text { with } \\
\text { periodontitis }\end{array}$ \\
\hline $15-19$ & 839 & 99.1 & 0.9 & 720 & 91.7 & 8.3 \\
\hline $20-24$ & 933 & 98.5 & 1.5 & 823 & 85.4 & 14.6 \\
\hline $25-29$ & 775 & 98.5 & 1.5 & 733 & 82.2 & 17.2 \\
\hline $30-34$ & 647 & 98.0 & 2.0 & 545 & 70.8 & 29.2 \\
\hline $35-39$ & 627 & 96.6 & 3.4 & 533 & 63.1 & 36.9 \\
\hline $40-44$ & 654 & 97.8 & 2.2 & 514 & 62.8 & 37.2 \\
\hline $45-49$ & 438 & 96.6 & 3.4 & 349 & 49.2 & 40.8 \\
\hline $50-54$ & 478 & 95.8 & 4.2 & 336 & 57.0 & 43.0 \\
\hline $55-59$ & 437 & 95.8 & 4.2 & 248 & 47.7 & 52.3 \\
\hline $60-64$ & 432 & .95 .1 & 4.9 & 150 & 51.5 & 48.5 \\
\hline $65-69$ & 1532 & 95.5 & 4.5 & 481 & 47.6 & 52.4 \\
\hline$\geq 70$ & 1165 & 96.3 & 3.7 & 301 & 52.2 & 47.8 \\
\hline
\end{tabular}

*Determined by examiner judgment of treatment need for periodontitis.

**Determined by examiner judgment of treatment need for calculus and oral deposits. 
TABLE 3

AGE-SPECIFIC PREVALENCE AND ESTIMATED INCIDENCE RATE* OF PERIODONTITIS IN NATIONAL SAMPLE OF 14690 SUBJECTS AGED 15-74, UNITED STATES, 1971-74

\begin{tabular}{|c|c|c|c|c|c|c|}
\hline \multirow[b]{3}{*}{ Age Group } & \multicolumn{2}{|c|}{ Overall } & \multicolumn{4}{|c|}{ Oral Hygiene } \\
\hline & \multirow[b]{2}{*}{$\begin{array}{c}\text { Prevalence } \\
\%\end{array}$} & \multirow[b]{2}{*}{ Incidence } & \multicolumn{2}{|c|}{ Good } & \multicolumn{2}{|c|}{ Poor } \\
\hline & & & $\begin{array}{c}\text { Prevalence } \\
\% \\
\end{array}$ & Incidence & $\begin{array}{c}\text { Prevalence } \\
\% \\
\end{array}$ & Incidence \\
\hline $15-19$ & 4.2 & 0.037 & 0.9 & 0.006 & 8.3 & 0.069 \\
\hline $20-24$ & 7.7 & 0.014 & 1.5 & 0.000 & 14.6 & 0.030 \\
\hline $25-29$ & 9.0 & 0.063 & 1.5 & 0.005 & 17.2 & 0.145 \\
\hline $30-34$ & 14.7 & 0.042 & 2.0 & 0.014 & 29.2 & 0.096 \\
\hline $35-39$ & 18.3 & 0.002 & 3.4 & 0.000 & 36.9 & 0.004 \\
\hline $40-44$ & 18.5 & 0.020 & 2.2 & 0.012 & 37.2 & 0.049 \\
\hline $45-49$ & 20.1 & 0.000 & 3.4 & 0.008 & 40.8 & 0.037 \\
\hline $50-54$ & 19.1 & 0.021 & 4.2 & 0.000 & 43.0 & 0.163 \\
\hline $55-59$ & 20.8 & 0.000 & 4.2 & 0.007 & 52.3 & 0.000 \\
\hline $60-64$ & 16.6 & 0.001 & 4.9 & 0.000 & 48.5 & 0.076 \\
\hline $65-69$ & 16.7 & 0.000 & 4.5 & 0.000 & 52.4 & 0.000 \\
\hline$\geq 70$ & 13.4 & - & 3.7 & - & 47.8 & - \\
\hline
\end{tabular}

*See text for explanation.

TABLE 4

LOGISTIC REGRESSION COEFFICIENT OF THE PROBABILITY OF HAVING PERIODONTITIS GIVEN ORAL HYGIENE LEVELS AND AGE

\begin{tabular}{lrcc}
\hline \hline & Coefficient & Standard Error & $\begin{array}{c}\text { Odds Ratio } \\
(95 \% \text { confidence interval) }\end{array}$ \\
\hline Intercept & -8.0392 & 0.1608 & \\
OHI & 3.0213 & 0.0740 & $20.52(17.75,23.72)$ \\
Age & 0.2111 & 0.0086 & $1.24(1.21,1.28)$ \\
\hline
\end{tabular}

TABLE 5

FITTED PREVALENCES OF PERIODONTITIS* IN THE NHANES I SAMPLE, BASED ON LOGISTIC REGRESSION ANALYSIS RESULTS, UNITED STATES, 1971-74

\begin{tabular}{ccc}
\hline & \multicolumn{2}{c}{ Oral Hygiene } \\
\cline { 2 - 3 } Age Group & Good & Poor \\
\hline $15-19$ & 0.008 & 0.144 \\
$20-24$ & 0.010 & 0.172 \\
$25-29$ & 0.012 & 0.204 \\
$30-34$ & 0.015 & 0.240 \\
$35-39$ & 0.019 & 0.281 \\
$40-44$ & 0.023 & 0.325 \\
$45-49$ & 0.028 & 0.373 \\
$50-54$ & 0.035 & 0.424 \\
$55-59$ & 0.042 & 0.476 \\
$60-64$ & 0.052 & 0.529 \\
$65-69$ & 0.063 & 0.581 \\
$\geq 70$ & 0.077 & 0.631 \\
\hline
\end{tabular}

*Estimated from coefficient derived from logistic regression (Table 4).

Becker et al., 1984), although healing of a periodontal pocket following surgery almost never results in the formation of significant amounts of new connective tissue attachment (Nyman et al., 1983; Lindhe et al., 1986). Other studies have demonstrated that a reduction in the probing depth measurement may not represent a gain in connective tissue attachment but rather a resolution of the inflammatory lesion in the gingiva (Polson et al., 1980; Van der Velden, 1980; Janson et al., 1981). Thus, while the first assumption has some questions around it, there is no firm evidence yet to reject it. Second, it can be assumed that mortality is the same for persons with and without periodontitis. The final assumption of stable disease in a stable population is reasonable: Douglass et al. (1983b), comparing the 1960-62 Health Examination Survey and the NHANES I survey of 1971-74, demonstrated a fairly constant
TABLE 6

ESTIMATED INCIDENCES OF PERIODONTITIS IN THE NHANES I SAMPLE, BASED ON FITTED PREVALENCES, UNITED STATES, 1971-74

\begin{tabular}{ccccc}
\hline \hline & \multicolumn{2}{c}{ Oral Hygiene } & & Relative Risk \\
\cline { 2 - 4 } Age Group & Good & Poor & EF & $(\%)$ \\
\hline $15-19$ & 0.002 & 0.033 & 17.2 & 94 \\
$20-24$ & 0.002 & 0.039 & 16.9 & 94 \\
$25-29$ & 0.003 & 0.046 & 15.8 & 93 \\
$30-34$ & 0.004 & 0.053 & 14.8 & 93 \\
$35-39$ & 0.004 & 0.062 & 14.1 & 93 \\
$40-44$ & 0.005 & 0.071 & 13.4 & 92 \\
$45-49$ & 0.007 & 0.081 & 12.2 & 91 \\
$50-54$ & 0.008 & 0.091 & 11.2 & 91 \\
$55-59$ & 0.010 & 0.101 & 10.2 & 90 \\
$60-64$ & 0.012 & 0.109 & 9.1 & 89 \\
$65-69$ & 0.015 & 0.120 & 8.2 & 88 \\
$\geq 70$ & - & - & & \\
\hline
\end{tabular}

*Etiologic fraction among exposed (see text for definition).

prevalence of destructive periodontal disease. Thus, although the model of Leske et al. (1981) was developed for the study of glaucoma, it appears to fit the periodontal disease model reasonably well.

Although the prevalence of periodontitis increases with age in the whole group (Tables 1 and 5), the increase in prevalence is much more pronounced in the poor-oral-hygiene stratum than in the good one when the data are stratified by oral hygiene status. Furthermore, analysis of the data (Table 6) shows that the incidence rates, throughout all age groups, are much higher among subjects with poor oral hygiene than among those with good oral hygiene, so the effect of age on the progression of periodontitis could be considered negligible when good oral hygiene is maintained. This conclusion is enhanced by the information in Table 4 , which shows a strong association between disease and oral hygiene (odds ratio $=20.52$, i.e., the odds of having the disease among subjects with poor oral hygiene is 20.52 times greater than among those with good oral hygiene), while the odds ratio of 1.24 indicates a weak association between the disease and age because the odds ratio is close to unity. Furthermore, it is interesting to note that estimated overall incidence reaches a maximum for periodontitis in the 25-29-year-old age group. This higher incidence is explained almost entirely by poor oral hygiene when the 25-29year-old age group is stratified by oral hygiene levels. These 
results agree with those of other studies, suggesting that periodontitis can be explained largely in terms of oral hygiene (Löe et al., 1978a, 1978b; Anerud et al., 1979; Burt et al., 1985), although even that long-held hypothesis still needs further investigation (Listgarten et al., 1985). While the evidence is that oral deposits are likely to be a major contributing cause of periodontitis, it is likely that their effect is mediated by host response to a greater or lesser extent.

This study supports the hypothesis that age is not a determinant of periodontitis when excellent oral hygiene is maintained, and it does so by deriving incidence from prevalence data. Based on the results of this investigation, it can be concluded that periodontitis is mainly related to the oral hygiene status of subjects and that age could be considered as a correlate rather than a risk factor.

The statistical method presented (Leske et al., 1981) could be a useful research tool in estimating age-specific incidence of periodontitis from prevalence data, given the difficulty of longitudinal studies. Like all statistical models, its utility depends upon the validity of the assumptions upon which it is based. While we have suggested that the assumptions underlying this particular model are valid, more research is required on the issue of irreversibility of periodontitis. Although the results of this study firmly support the role of plaque deposits in periodontitis, that issue also requires further investigation to determine plaque's role, relative to the host response, in the natural history of this condition.

(Results and conclusions are solely those of the authors and are not necessarily those of the National Center for Health Statistics.)

\section{REFERENCES}

ANERUD, A.; LÖE, H.; BOYSEN, H.; and SMITH, M. (1979): The Natural History of Periodontal Disease in Man. Changes in Gingival Health and Oral Hygiene Before 40 Years of Age, $J$ Periodont Res 14:526-540.

BECK, J.D.; LAINSON, P.A.; FIELD, H.M.; and HAWKINS, B.F. (1984): Risk Factors for Various Levels of Periodontal Disease and Treatment Needs in Iowa, Community Dent Oral Epidemiol $12: 17-22$

BECKER, W.; BECKER, B.E.; and BERG, L.E. (1984): Periodontal Treatment Without Maintenance; A Retrospective Study in $44 \mathrm{~Pa}-$ tients, $J$ Periodontol 55:505-509.

BECKER, W.; BERG, L.; and BECKER, B.E. (1979): Untreated Periodontal Disease: A Longitudinal Study, J Periodontol 50:234243.

BERKI, S.E.; LEPKOWSKI, J.N.; WYSZEWIANSKI, L.; LANDIS, J.R.; MAGILAVY, M.L.; McLAUGHLIN, G.; and MURT, H.A. (1985): High-volume and Low-volume Users of Health Services, United States, 1980. National Medical Care Utilization and Expenditure Survey. National Center for Health Statistics; DHHS Publ. No. (PHS) 86-20402, Series C; No. 2. Washington, D.C.: U.S. Government Printing Office.

BOYLE, W.D.; VIA, W.F.; and McFALL, W.T. (1973): Radiographic Analysis of Alveolar Crest Height and Age, $J$ Periodontol 44:236-243.

BURT, B.; EKLUND, S.; LANDIS, J.R.; LARKIN, F.; GUIRE, K.; and THOMPSON, F. (1982): Diet and Dental Health, A Study of Relationships: United States - 1971-1974. Hyattsville, Maryland: National Center for Health Statistics; DHHS Publ. No. (PHS)821675, Series 11; No. 225. Washington, D.C.: U.S. Government Printing Office.

BURT, B.A. (1985): The Social Epidemiology of Periodontal Disease. Paper presented at the American Academy of Periodontics Conference.

BURT, B.A.; ISMAIL, A.I.; and EKLUND, S.A. (1985): Periodontal Disease, Tooth Loss, and Oral Hygiene Among Older Americans, Community Dent Oral Epidemiol 13:93-96.
CHILTON, N.W. (1950): Some Public Health Aspects of Periodontal Disease, J Am Dent Assoc 40:23-33.

CHILTON, N.W. and MILLER, M.F. (1977): Diagnostic Methods and Epidemiology of Periodontal Disease, B. Klavan, R. Genco, H. Löe, R. Page, I. Stern, J. Thorpe, and E. Barrington, Eds., International Conference on Research in the Biology of Periodontal Disease, Chicago: University of Illinois, pp. 94-118.

DOUGLASS, C.W.; GILLINGS, D.; SOLLECITO, W.; and GAMMON, M. (1983a): The Potential for Increase in the Periodontal Diseases in the Aged Population, J Periodontol 54:721-730.

DOUGLASS, C.W.; GILLINGS, D.; SOLLECITO, W.; and GAMMON, M. (1983b): National Trends in the Prevalence and Severity of the Periodontal Diseases, J Am Dent Assoc 107:403-412.

GOODSON, J.M.; TANNER, A.C.R.; HAFFAJEE, A.D.; SORNBERGER, G.C.; and SOCRANSKY, S.S. (1982): Patterns of Progression and Regression of Advanced Destructive Periodontal Disease, $J$ Clin Periodontol 9:472-481.

GREENE, J.C. and VERMILLION, J.R. (1964): The Simplified Oral Hygiene Index, $J$ Am Dent Assoc 68:7-13.

HAFFAJEE, A.D.; SOCRANSKY, S.S.; and GOODSON, J.M. (1982): Periodontal Disease Activity, J Periodont Res 17:521-522.

HUGOSON, A. and JORDAN, T. (1982): Frequency Distribution of Individuals Aged 20-70 Years According to Severity of Periodontal Disease, Community Dent Oral Epidemiol 10:187-192.

IMERY, P.B. (1986): Considerations in the Statistical Analysis of Clinical Trials in Periodontitis, $J$ Clin Periodontol 13:517-528.

ISMAIL, A.; BURT, B.; and EKLUND, S. (1983): Epidemiologic Patterns of Smoking and Periodontal Disease in the United States, J Am Dent Assoc 106:617-621.

JANSON, J.; PILOT, T.; and CORBA, N. (1981): Histologic Evaluation of Probe Penetration during Clinical Assessment of Periodontol Attachment Levels, J Clin Periodontol 8:98-106.

KELLEY, J.E. and HARVEY, C.R. (1979): Basic Data on Dental Examination Findings of Persons 1-74 Years, U.S., 1971-1974. National Center for Health Statistics; NHEW Publ. No. (PHS) 79 1662, Series 11, No. 214. Washington, D.C.: U.S. Government Printing Office.

KLEINBAUM, D.G.; KUPPER, L.L.; and MORGENSTERN, H. (1982): Epidemiologic Research Principles and Quantitative Methods, Belmont, CA: Lifetime Learning Publishers, pp. 1939.

LAST, J., Ed. (1983): A Dictionary of Epidemiology, New York: Oxford University Press, pp. 7-34.

LESKE, M.C.; EDERER, F.; and PODGOR, M. (1981): Estimating Incidence From Age-specific Prevalence in Glaucoma, $A m J$ Epidemiol 113:606-613.

LINDHE, J.; HAFFAJEE, A.D.; and SOCRANSKY, S.S. (1983): Progression of Periodontal Disease in Adult Subjects in the Absence of Periodontal Therapy, $J$ Clin Periodontol 10:433-442.

LINDHE, J.; SOCRANSKY, S.; and WENNSTROM, J. (1986): Design of Clinical Trials of Traditional Therapies of Periodontitis, $J$ Clin Periodontol 13:488-497.

LISTGARTEN, M.A.; SCHIFTER, C.C.; and LASTER, L. (1985): 3-year Longitudinal Study of the Periodontol Status of an AduIt Population with Gingivitis, $J$ Clin Periodontol 12:225-238.

LÖE, H.; ANERUD, A.; BOYSEN, H.; and SMITH, M. (1978a): The Natural History of Periodontal Disease in Man: Study Design and Baseline Data, $J$ Periodont Res 13:550-563.

LÖE, H.; ANERUD, A.; BOYSEN, H.; and SMITH, M. (1978b): The Natural History of Periodontal Disease in Man. The Rate of Periodontal Destruction Before 40 Years of Age, $J$ Periodontol 49:607-620.

McHUGH, W.D.; CAFFESSE, R.G.; CATON, J.G.; HAZEN, S.P.; MELLONIG, J.T.; PIHLSTROM, B.L.; RANNEY, R.R.; ROBERTSON, P.B.; and SCHLUGER, S. (1982): Proceedings of the State of the Art Workshop, J Periodontol 53:475-501.

NYMAN, S.; LINDHE, J; and KARRING, T. (1983): Reattachment-New Attachment. In: Textbook of Clinical Periodontology, J. Lindhe, Ed., Copenhagen:Munksgaard, pp. 410-432.

POLSON, A.M.; CATON, J.G.; YEAPLE, R.N.; and ZANDER, H.A. (1980): Histological Determination of Probe Tip Penetration into Gingival Sulcus of Humans using an Electronic Pressure Sensitive Probe, $J$ Clin Periodontol 7:479-488.

RAMFJORD, S.P.; EMSLIE, R.D.; GREENE, J.C.; HELD, A.J.; 
and WAERHAUG, J. (1968): Epidemiological Studies of Periodontol Disease, Am J Publ Hlth 58:1713-1722.

RUSSELL, A.L. (1956): A System of Classification and Scoring for Prevalence Surveys of Periodontol Disease, $J$ Dent Res 35:350359.

RUSSELL, A.L. (1967): The Periodontal Index, J Periodontol 38:585591.

SCHERP, H. (1964): Current Concepts in Periodontal Research: Epidemiological Contributions, J Am Dent Assoc 68:667-675.

SHEIHAM, A. (1979): The Epidemiology of Dental Caries and Periodontal Disease. Paper given at the symposium "Prevention of Major Dental Disorders," Marabou, Sundbyberg, Sweden.

SOCRANSKY, S.S.; HAFFAJEE, A.D.; GOODSON, J.M.; and LINDHE, J. (1984): New Concepts of Destructive Periodontal Disease, $J$ Clin Periodontol 1 1:21-31.
SUOMI, J.D.; GREENE, J.C.; VERMILLION, J.R.; DOYLE, J.; CHANG, J.J.; and LEATHERWOOD, F.C. (1971): The Effect of Controlled Oral Hygiene Procedures on the Progression of Periodontol Disease in Adults: Results After Third and Final Year, $J$ Periodontol 42:152-160.

VAN DER VELDEN, V. (1980): The Influence of Periodontal Health on Probing Depth and Bleeding Tendency. $J$ Clin Periodontol $7: 123-139$.

WAERHAUG, J. (1966): Epidemiology of Periodontal Disease Review of Literature. In: World Workshop in Periodontics, S.P. Ramfjord, D.A. Kerr, and M.M. Ash, Eds., Ann Arbor: University of Michigan, pp. 181-211.

WORLD HEALTH ORGANIZATION (1978): Epidemiology, Etiology, and Prevention of Periodontal Diseases. Technical Report Series No. 621. Geneva: WHO. 